Jinchao Li, Fei Gao*, Jiaguo Lu, and Tingye Tao

\title{
Deformation monitoring and prediction for residential areas in the Panji mining area based on an InSAR time series analysis and the GM-SVR model
}

https://doi.org/10.1515/geo-2019-0058

Received Nov 07, 2018; accepted Aug 14, 2019

\begin{abstract}
Underground coal mining activities often cause ground subsidence and damage to surface construction, which seriously threatens the lives and property of residents in mining areas. In this paper, the deformation of the Yang Juzhuang village, which is a residential area in the Huainan mining area (China), was monitored through an interferometric synthetic aperture radar (InSAR) time series analysis. The vertical displacements were detected using thirteen Sentinel-1A images that were acquired between December 2016 and May 2017. The validity and applicability of the method are verified by comparing the acquired images with the GPS measurement results. Because of the deformation characteristics of the mining area, a prediction model that is combined with a grey support vector machine regression (GM-SVR) is proposed, and the practical effects of the model are verified using the deformation monitoring results of the study area. The combination of this model and SBAS-InSAR provides rapid dynamic monitoring and enables the issuance of disaster warnings in the region.
\end{abstract}

Keywords: SBAS-InSAR; Disaster warning; Settlement prediction; Sentinel-1A; GPS

\footnotetext{
*Corresponding Author: Fei Gao: Hefei University of Technology,
School of Civil and Hydraulic Engineering, Hefei, Anhui, China;

School of Civil and Hydraulic Engineering, Hefei, Anhui, China; Email: 502406358@qq.com

Jinchao Li, Tingye Tao: Hefei University of Technology, School of Civil and Hydraulic Engineering, Hefei, Anhui, China

Jiaguo Lu: The 38th Research Institute of China Electronics Technology Group Corporation, Hefei, Anhui, China
}

Ә Open Access. @ 2019 J. Li et al., published by De Gruyter. License

\section{Introduction}

Large-scale underground coal mining activities can easily cause ground subsidence and damage the surface structure [1, 2]. Mining activities can unintentionally induce geological disasters such as landslides, subsidence, and ground fissures, which seriously threaten the sustainable development of the region [3-5]. As one of the largest coal-production countries in the world, China's geological disasters in coal mining areas such as ground subsidence, ground collapse and ground water accumulation have been continuous and urgent problems for mining enterprises and local governments [6, 7]. Practical experience has proven that when cumulative amounts of surface deformation in a mining area reaches a certain threshold, a catastrophe will occur under numerous conditions related to weather, geological activities, or human activities $[8,9]$. Therefore, in order to ensure uninterrupted mining activities and to avoid the loss of mining area resident's lives and property, long-term and effective environmental monitoring and prediction for the surface of a mining area is required [10,11]. Additionally, we require a means to understand the characteristics and laws of surface deformations caused by mining. In addition to enhancing the scientific and rational mining capacities for coal resources, mining enterprises should intensify the work of prediction and measurement of the extent of subsidence to reduce risk and mitigate possible hazards [12,13].

In recent years, compared with the traditional sparse distribution and time-consuming measurement techniques of GPS and levelling [14-17], differential interferometric synthetic aperture radar (D-InSAR) with its continuous coverage, high accuracy, and high degree of automation, has become an effective means of obtaining surface deformation information [18, 19]. Many scholars around the world have conducted extensive research on surface deformation monitoring using D-InSAR. The accuracy of D-InSAR to the millimetre-level is verified [20]. However, 
D-InSAR is significantly affected by spatiotemporal coherence and atmospheric delay effects [21]. Time-continuous subsidence monitoring results are unobtainable. To overcome the drawbacks and limitations of conventional DInSAR, the Small Baseline Subset (SBAS) technique has been proposed [22]. Currently, SBAS technology is widely used in the monitoring and analysis of deformations caused by seismic events [23, 24], volcanic activity [25], glaciers [26, 27], groundwater exploitation [28, 29] and mining subsidence [30, 31]. The SBAS approach mainly focuses on large-scale and long-span deformation monitoring and analysis [32-34]. Although the performance of SBAS in monitoring small-scale deformations in an urban context has only recently been successfully validated [35]. There are few published articles on using SBAS for continuous dynamic monitoring analysis of residential areas. For disaster prediction, in 2016, Shafaei [36] used the SVR model to predict fluctuations on lake water surfaces. In 2016, Fattahi et al. (2016) [37] combined pressuremeter tests and the predictive SVR model to predict the deformation modulus of a rock mass. In addition, Hong et al. (2016) [38] used the model to predict landslide hazards. However, there are few studies on the rapid monitoring and disaster prediction of deformations of residential areas in mining areas that examine the use of the SBAS-InSAR technology and prediction model. Therefore, to facilitate safe mining under buildings, to timeously understand surface deformation laws, to predict the demand for possible disaster locations and to rationally arrange time for relocating mining villages, this study explores monitoring methods that combine SBAS-InSAR and GM-SVR.

In this paper, SBAS-InSAR and 13 Sentinel-1 images with revisiting periods of 12 days were applied to monitor the deformation of the residential area in Yang juzhuang (Huainan, China). According to the actual deformation characteristics of the mining subsidence, a combined prediction model based on a grey model and support vector machine regression is proposed. Furthermore, combined with the continuous dynamic monitoring results obtained by SBAS-InSAR, a high-precision deformation prediction of the mining area is performed through the model.

\section{Materials and Methods}

\subsection{Study area and data preparation}

In this work, the village of Yang juzhuang in the Huainan mining area was selected as a case study (Figure 1). The Huainan coalfield is located in the central Anhui Province,
East China, which has a mining history that covers the past 100 years. It is one of the regions that has been noted in Chinese history for the early exploitation and use of coal resources. The rich coal resources in this region make up for a shortage of energy in the eastern part of China. The Huainan coalfield plays an irreplaceable role in ensuring the sustainable and healthy development of the national economy [39]. Mining activities in the Huainan area began in the 1920s. However, due to continuous improvement in the development of coal resources in mining areas, the geography of the coal mining area has also increased sharply. As a result, the spatial extent of surface subsidence in the Huainan coalfield was only $90 \mathrm{~km}^{2}$ in 2004, which grew to $150 \mathrm{~km}^{2}$ in 2010 and is still increasing [40]. The urban and rural environments of the mining area are deteriorating, and the lives of the people in the mining areas have been greatly affected. All of these problems have created security issues, which have attracted the attention of the relevant local authorities.

Sentinel-1 is the first of the Copernicus Programme satellite constellation studies conducted by the European Space Agency. Following ERS and ENVISAT it is another C-band remote sensing satellite of great importance that collects data in every weather condition, day or night. The first satellite, Sentinel-1A, launched on April 3rd, 2014. Sentinel-1 provided a data continuity bridge from the ERS and Envisat missions, with further enhancements in terms of revisits, coverage, timeliness and reliability of service. There are wide ranges of applications for the data, which include land monitoring (agriculture, forestry) [41, 42], marine monitoring (sea-ice levels, ocean oil spills, ship activity) [43], and emergency responses (flooding, landslide and volcanic) [44]. In contrast to the traditional Strip Mape (SM) mode and ScanSAR mode, the Sentinel-1 data adopts a new Interferometric Wide Swath (IW) mode of terrain observation by employing a progressive scans (TOPS) technology. In this paper, Yang Juzhuang was selected as the study area (Figure 1). A total of 13 C-band Sentinel-1 IW images from December 27, 2016 to May 20, 2017 were collected (polarization: VV, revisit period: 12 days, orbit configuration: ascending). The acquisition dates and other relevant parameters are shown in Table 1. The corresponding Sentinel-1 Precise Orbit Ephemerides were collected.

\subsection{Rationale of the SBAS-InSAR technique}

An InSAR time series analysis was developed on the basis of conventional InSAR technology. Estimating the parameters of the phase statistical characteristics of the multitemporal SAR data can effectively reduce the errors intro- 


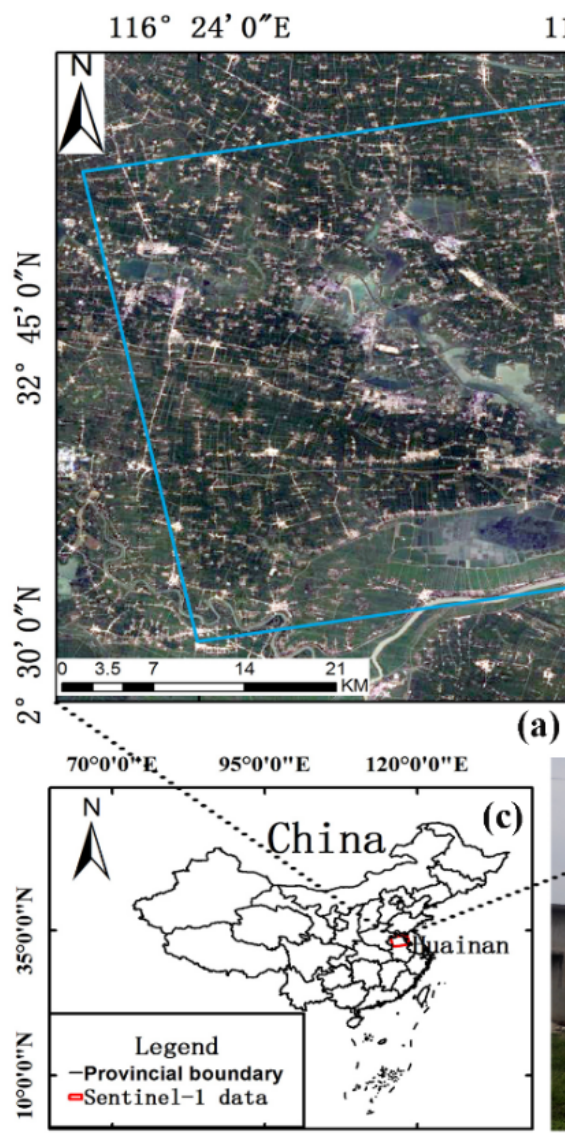

$116^{\circ} 42^{\prime} 0^{\prime \prime} \mathrm{E}$

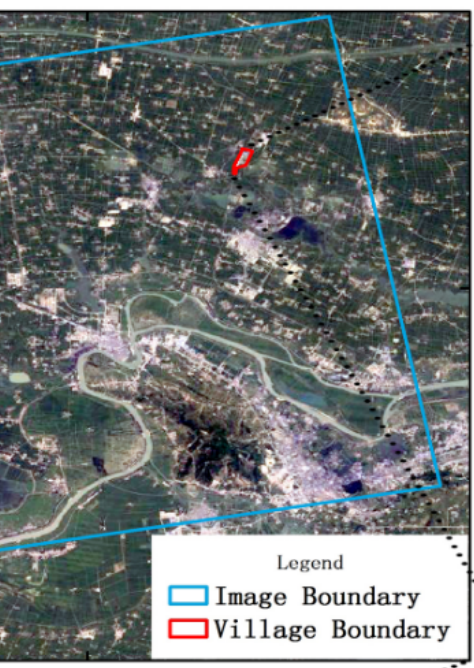

(a)

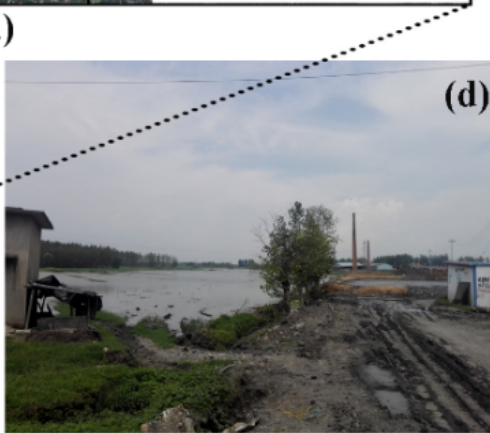

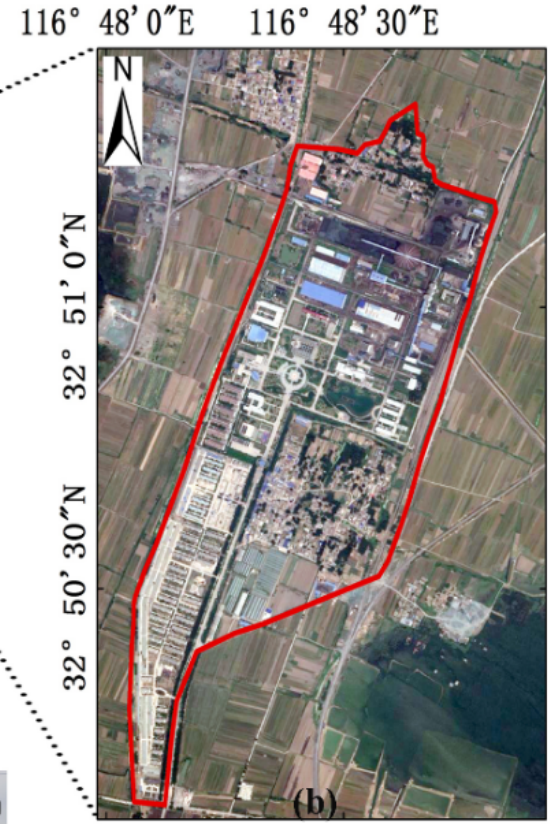

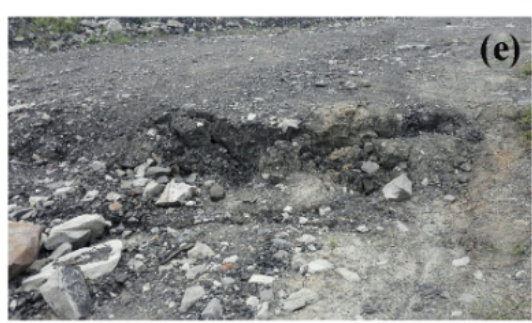

Figure 1: A regional overview of the village of Yang Juzhuang, Huainan, China: (a, b, c) location of the study area, (d) the waterlogged area, and (e) the damaged road

Table 1: Parameters of Sentinel-1 images of the Huainan mining area

\begin{tabular}{cccccccc}
\hline NO. & Acquisition date & Product & Beam model & NO. & Acquisition date & Product & Beam model \\
\hline $\mathbf{1}$ & 27 Dec 2016 & SLC & TOPS & 8 & 21 Mar 2017 & SLC & TOPS \\
$\mathbf{2}$ & 08 Jan 2017 & & & 9 & $02 \mathrm{Apr} 2017$ & & \\
$\mathbf{3}$ & 20 Jan 2017 & & & 10 & $14 \mathrm{Apr} 2017$ & & \\
$\mathbf{4}$ & 01 Feb 2017 & & 11 & $26 \mathrm{Apr} 2017$ & & \\
$\mathbf{5}$ & 13 Feb 2017 & & 12 & 08 May 2017 & & \\
$\mathbf{6}$ & 25 Feb 2017 & & 13 & 20 May 2017 & & \\
$\mathbf{7}$ & 09 Mar 2017 & & & & & & \\
\hline
\end{tabular}

duced by factors such as atmospheric delays and low coherence in the interferogram. The basic principle of SBAS, which is one of the branches of the time-series InSAR technology, is to use the observation results of the conventional D-InSAR monitoring as a single observation value, and then obtain a high-precision deformation time series according to the least squares method. A detailed discussion of this approach and its implementation can be found in Lanari et al. (2004) [45]; blow is a brief summary.
Considering a set of $N+1$ SAR images acquired at the ordered times $\left(t_{0}, t_{1} \ldots, t_{n}\right)$ over an area of interest, then $M$ interferograms will be generated with small temporal and spatial baselines to minimize the decorrelation phenomena. In addition, $M$ meets the following criteria [46]:

$$
\frac{N+1}{2} \leq M \leq N\left(\frac{N+1}{2}\right)
$$

assuming that the interferogram $\mathrm{j}$ generated from the time $\mathrm{t}_{A}, \mathrm{t}_{B}\left(\mathrm{t}_{B}>\mathrm{t}_{A}\right)$. After removing the effects of the flat effect 


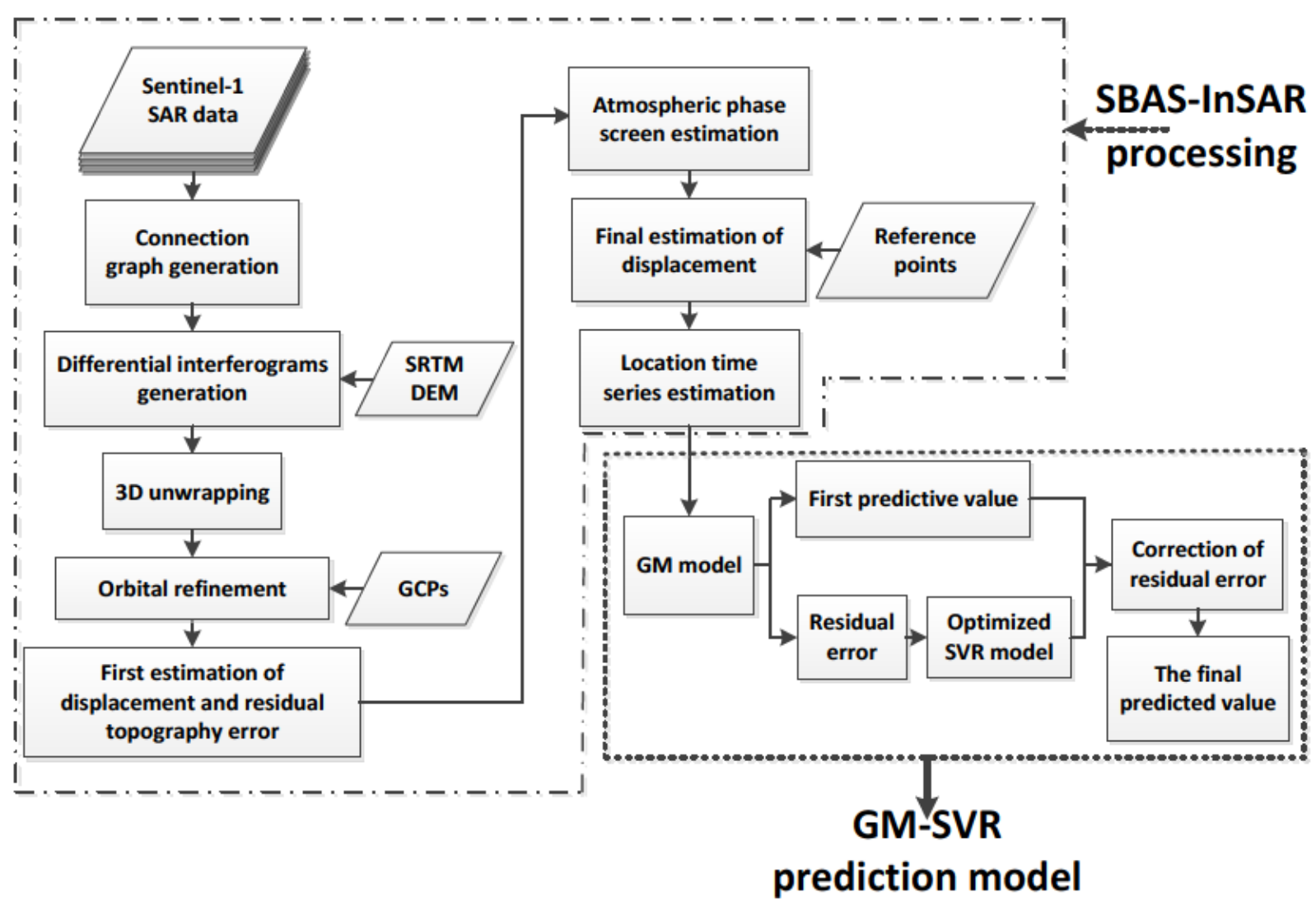

Figure 2: Processing flowchart of mine deformation monitoring and prediction in mining area based on SBAS-InSAR technology and GM-SVR model

(the reference ellipsoid) and the topographic phase, the interferometric phase of any pixel in the interferogram $\mathrm{j}$ can be expressed as:

$$
\begin{aligned}
\delta \varphi_{j} & =\varphi\left(t_{B}\right)-\varphi\left(t_{A}\right)=\varphi_{d e f, j}+\varphi_{t o p o, j}+\varphi_{a t m, j} \\
& +\varphi_{\text {noise }, j}
\end{aligned}
$$

where $\varphi\left(t_{B}\right)$ and $\varphi\left(t_{A}\right)$ are the phase values of the SAR images at time tB and tA, respectively; $\varphi_{d e f, j}$ is the deformation phase along the line of sight (LOS) direction; $\varphi_{\text {topo }, j}$ is the phase error due to the inaccuracy of the reference DEM; $\varphi_{a t m, j}$ is the atmospheric delay phase; and $\varphi_{\text {noise }, j}$ is the noise effects phase.

The time series deformation, calculated with the SBASInSAR algorithm can be represented as follows:

$$
B v=\delta \varphi
$$

where B is an $M \times N$ matrix and $\delta \varphi$ is a vector which represents the interferometric phase values. When the coeffcient matrix $B$ is a full rank $(M \geq N)$, the deformation rate can be obtained by the least squares method, and when $\mathrm{M}<\mathrm{N}$, the matrix $\mathrm{B}$ has a rank deficit. The singular value decomposition (SVD) is used to obtain the deformation rate.
Finally, based on the time interval of the image, we can determine the deformation of the corresponding time period.

The SBAS-InSAR process includes the following key steps:

1. The master image was selected by comprehensively considering a temporal baseline, a spatial baseline and a Doppler centroid frequency baseline, and the interferogram connection diagram was generated according to the small baseline set principle.

2. For each small baseline pair, we do differential interferometry, and select the appropriate algorithm to unwrap the interferogram.

3. We artificially remove some interferometric pairs with very poor interferometry quality and select ground control points for orbit refining and reflattening.

4. By establishing a model on a pixel point with good coherence, the deformation and deformation rate of the target points are extracted by the SVD. The detailed processing steps are shown in Figure 2. 


\subsection{Establishment of GM-SVR prediction model}

Due to the destruction of in situ stress distributions in the mining area, the overall structure of the surrounding rock and overlying strata is affected, and under the influence of some external factors, nonlinear deformations of the ground is caused during the mining process. Since the deformation process contains many unknown factors, the deformation process is very complicated. Therefore, the traditional single linear or single nonlinear forecasting model is used for forecasting, which is not very practical and cannot achieve the desired prediction effect. In this paper, based on the GM $(1,1)$ model and the optimized Support Vector Machine Regression model, a combined prediction model GM-SVR is established. This model makes use of the linear prediction advantages of the grey model and the excellent generalization abilities and learning abilities of the nonlinear data of the support vector machine model to perform high-performance predictions of the ground subsidence in the mining area.

Generally, a system with poor and incomplete information is called a grey system. Before establishing the grey prediction model, all original time series need to be regarded as having grey amounts with grey features. The randomness of the initial data are weakened by the prepreprocessing of chaotic data into ordered data. Then, differential equations are established to predict future development trends. The advantage of the model is that for systems with small data samples or inaccurate information, the orderly mathematical rules in the internal continuous change process can be excavated, and the model has a wide range of adaptations. Detailed principles can be found in Mao et al. 2006 [47]. This article only gives a brief introduction.

By accumulating the original data, a new data sequence is generated. The fluctuations and randomness of the new data series are weakened [48]:

$$
X^{(1)}\left(t_{1}\right)=\left[X^{(1)}\left(t_{1}\right), X^{(1)}\left(t_{2}\right), \cdots \cdots, X^{(1)}\left(t_{n}\right)\right]
$$

where $X^{(1)}$ are the 1-AGO (accumulated generating operator) of the initial data. Therefore, the GM $(1,1)$ model can be established as Eq. (5) (a differential equation):

$$
\frac{d x^{(1)}}{d t}+\alpha x^{(1)}=u
$$

Using the least squares method, the values of the parameters $\alpha$ and $u$ can be obtained. Therefore, $\hat{X}^{(1)}(t+1)$ can be obtained by using Eq. (6).

$$
\hat{X}^{(1)}(t+1)=\left(X^{(0)}(1)-\frac{u}{\alpha}\right) e^{-\alpha t}+\frac{u}{\alpha}
$$

where $\hat{X}^{(1)}(t+1)$ is the predicted data. Finally, the last predicted data can be obtained by $\hat{X}^{(1)}(t+1)$ minus $\hat{X}^{(1)}(t)$.

Support vector machine (SVM) is a new method in data mining. This method is based on a general learning method and a statistical learning theory that specializes in the study of small samples. Support vector machine maps nonlinear problems in low-dimensional space to high-dimensional space and solves nonlinear problems in low-dimensional space through decision functions in high-dimensional space. Additionally, the support vector machine has a corresponding penalty mechanism to prevent the occurrence of overfitting. SVM not only considers the requirements of the approximation accuracy but also considers the complexity of the approximation function and can obtain optimal result under limited conditions. Only a brief summary is presented here. The SVM objective function can be expressed as $[49,50]$ :

$$
\frac{1}{2}\|\omega\|^{2}+C \sum_{i=1}^{n}\left(\xi_{i}+\xi_{i}^{\star}\right)
$$

where $\omega$ denotes the direction vector, $\mathrm{C}$ denotes the adjustment factor, and $\xi_{i}$ and $\xi_{i}^{*}$ are slack variables. The deviation of the non-insensitive $(\epsilon)$ out-of-band training sample points is measured by introducing slack variables. Then, a Lagrange multiplier $\alpha$ was introduced, and samples were mapped to high-dimensional Hilbert space according to KKT (Karush-Kuhn-Tucker constraint). Finally, a linear regression is applied to the transformed results in the highdimensional space to obtain a nonlinear regression function.

In this paper, the initial fitting of samples is carried out through the GM $(1,1)$ model to grasp the original internal development trend of the samples. Then, the residual value sequence is obtained by comparing the predicted value of the grey model with the initial sample. Normally, the deformation process of the surface of the mining area is very complicated, and the fluctuations in the data that are obtained by monitoring are relatively large. Therefore, the nonlinearity of the residual sequence predicted by the grey model is usually high. Based on this, an optimized SVM regression model is used to establish the residual correction model and further explore the internal rules of the residual series. The support vector machine regression model is optimized by searching the optimal penalty parameter $\mathrm{c}$ and the variance $\mathrm{G}$ in kernel function by the grid search method. Finally, by training the sample in the model, the predicted value of the grey model and the model residual correction of the SVR are obtained. The sum of the predicted value and the residual error correction value is the final predicted value of the combined model. The techni- 
cal process of the deformation prediction combined with SBAS-InSAR is shown in Figure 2.

\section{Results}

\subsection{Data processing and analysis of deformation monitored by the SBAS-InSAR}

In this paper, the SBAS-InSAR method was used to process Sentinel-1 data. This section describes the main parameters and processing steps and provides details of the analysis of the deformation of the study area.

First, an interference connection graph was generated with a 120-m perpendicular baseline threshold and a 60day temporal baseline. Sixty-three interferometric pairs were obtained, and the relative relationship between the time and space position of the connection graph is shown in Figure 3. Next, according to the connection relationship of the connection diagrams, a differential interferometry set is generated, precision orbit data is used to remove the flat effect, and the external Shuttle Radar Topography Mission digital elevation model SRTM3 DEM data are used to eliminate topography phase [51]. The phase unwrapping of the small baseline interferogram was carried out by the minimum cost flow method. Subsequently, based on the stability of the amplitude and phase, the stability point in the study area was selected. Then, a third-order polynomial model was used for orbit refinement and to remove the trend phase caused by the orbital error. Finally, deformation rate inversion and geocoding were performed, the atmospheric delay phase of the coherent point is separated according to the temporal and spatial characteristics of the atmospheric phase, and the line-of-sight deformation is segmented according to the cosine of the incident angle to obtain the ground vertical displacement.

Figure 4 shows a time series diagram of deformations with typical representative characteristics in the study area from December 27, 2016 to May 20, 2017. All images show the cumulative amount of deformation using December 7, 2016 as the reference time. The upper right corner of each figure shows the acquisition time of the image. Figure 5 shows the deformation rate of the study area. From Figure 4 and Figure 5, the maximum cumulative vertical subsidence caused by mining in the entire residential area during the monitoring period is $48 \mathrm{~mm}$; the average cumulative displacement is $-17.8 \mathrm{~mm}$; the maximum deformation rate reaches $-90 \mathrm{~mm} /$ year.

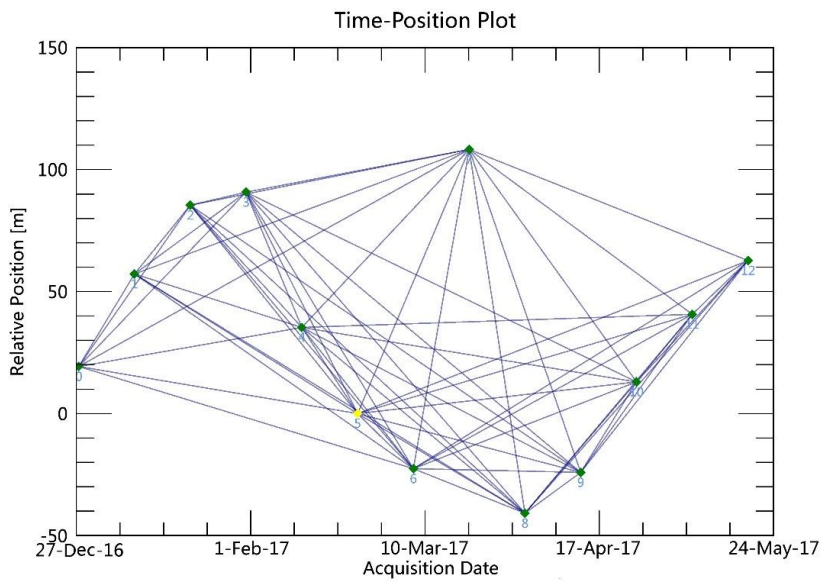

Figure 3: Temporal and spatial baseline connection diagram of interferogram pairs

The accuracy of SBAS in monitoring deformation that is caused by mining is verified by using the doubledifferenced static positioning measurement of BDS/GPS combined system (hereinafter referred to as GPS). The accuracy of the elevation direction of the $1 \mathrm{~h}$ solution of the GPS system is better than $4 \mathrm{~mm}$, which meets the requirements of the deformation monitoring accuracy of this residential area. The spatial distribution of the site is shown in Figure 5. Figure 6 shows the comparison of the observation results of the deformation sequence at the observation points between the SBAS-InSAR technology and the GPS technology. Analysis of Figure 6 reveals that the maximum absolute error, relative error and average absolute error of vertical displacement between the measurement results of SBAS-InSAR and GPS at the G1 point are $4.33 \mathrm{~mm}, 2.38 \mathrm{~mm}$ and $2.01 \mathrm{~mm}$ respectively, and at the $\mathrm{G} 2$ point, they are 2.87 $\mathrm{mm}, 1.61 \mathrm{~mm}$ and $1.34 \mathrm{~mm}$, respectively.

\subsection{Assessment of prediction model}

The time series data of the observation points (spatial distribution shown in Figure 5) that were obtained by the SBAS-InSAR technology were input to the GM-SVR model for fitting and prediction. To verify the performance of the proposed GM-SVR model for deformation predictions in the mining area, two other schemes are established in this paper for comparison: scheme one, using a single GM $(1,1)$ model for prediction; scheme two, using a single Support Vector Machine Regression model for prediction. From December 27, 2016 to April 02, 2017, eight settlement data with a time interval of 12 days were used as training samples for modelling, and four settlement data from April 02, 2017 to May 20, 2017 were used as a test sample for the prediction 
Table 2: Comparison of fitting results in each model of $\mathrm{G} 1 / \mathrm{mm}$

\begin{tabular}{|c|c|c|c|c|c|c|c|c|}
\hline \multirow[t]{2}{*}{ No. } & \multirow{2}{*}{$\begin{array}{l}\text { Acquisition } \\
\text { date }\end{array}$} & \multirow{2}{*}{$\begin{array}{c}\text { SBAS } \\
\text { results } \\
/ \mathrm{mm}\end{array}$} & \multicolumn{2}{|c|}{ GM $(1,1)$ model } & \multicolumn{2}{|c|}{ SVR model } & \multicolumn{2}{|c|}{ GM-SVR model } \\
\hline & & & $\begin{array}{l}\text { Fitting } \\
\text { value }\end{array}$ & $\begin{array}{l}\text { Relative } \\
\text { error } / \%\end{array}$ & $\begin{array}{l}\text { Fitting } \\
\text { value }\end{array}$ & $\begin{array}{l}\text { Relative } \\
\text { error } / \%\end{array}$ & $\begin{array}{l}\text { Fitting } \\
\text { value }\end{array}$ & $\begin{array}{l}\text { Relative } \\
\text { error } / \%\end{array}$ \\
\hline 1 & 2017.01 .08 & 7.57 & 7.57 & 0 & 7.69 & 1.59 & 7.59 & 0.26 \\
\hline 2 & 2017.01 .20 & 10.48 & 11.24 & 7.25 & 9.83 & -6.2 & 10.45 & -0.29 \\
\hline 3 & 2017.02 .01 & 12.13 & 13.51 & 11.38 & 12.64 & 4.2 & 12.39 & 2.14 \\
\hline 4 & 2017.02 .13 & 15.89 & 16.24 & 2.2 & 16.01 & 0.76 & 15.86 & -0.19 \\
\hline 5 & 2017.02.25 & 19.58 & 19.53 & -0.26 & 19.79 & 1.07 & 20.67 & 5.57 \\
\hline 6 & 2017.03 .09 & 25.75 & 23.47 & -8.85 & 23.82 & -7.5 & 25.72 & -0.12 \\
\hline 7 & 2017.03 .21 & 29.66 & 28.21 & -4.89 & 27.9 & -5.93 & 29.68 & 0.07 \\
\hline 8 & 2017.04 .02 & 31.73 & 33.91 & 6.87 & 31.84 & 0.35 & 31.75 & 0.06 \\
\hline
\end{tabular}
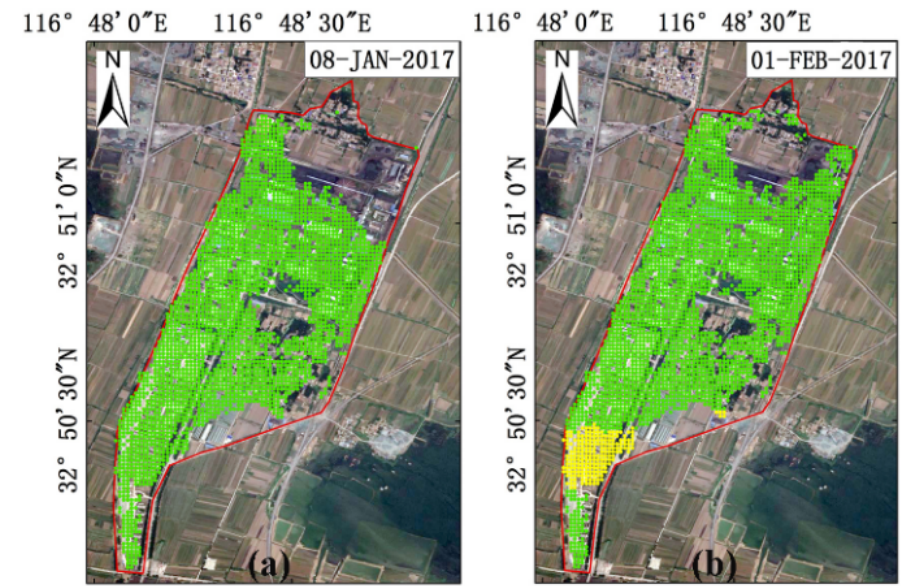

$116^{\circ} 48^{\prime} 0^{\prime \prime} \mathrm{E} \quad 116^{\circ}-48^{\prime} 30^{\prime \prime} \mathrm{E}$

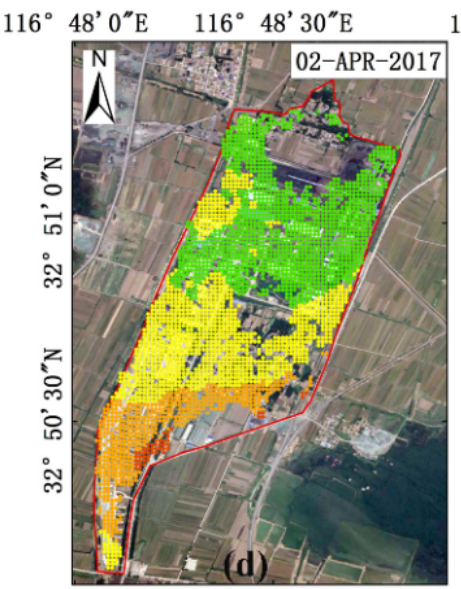

$116^{\circ} 48^{\prime} 0^{\prime \prime} \mathrm{E} \quad 116^{\circ} 48^{\prime} 30^{\prime \prime} \mathrm{E}$
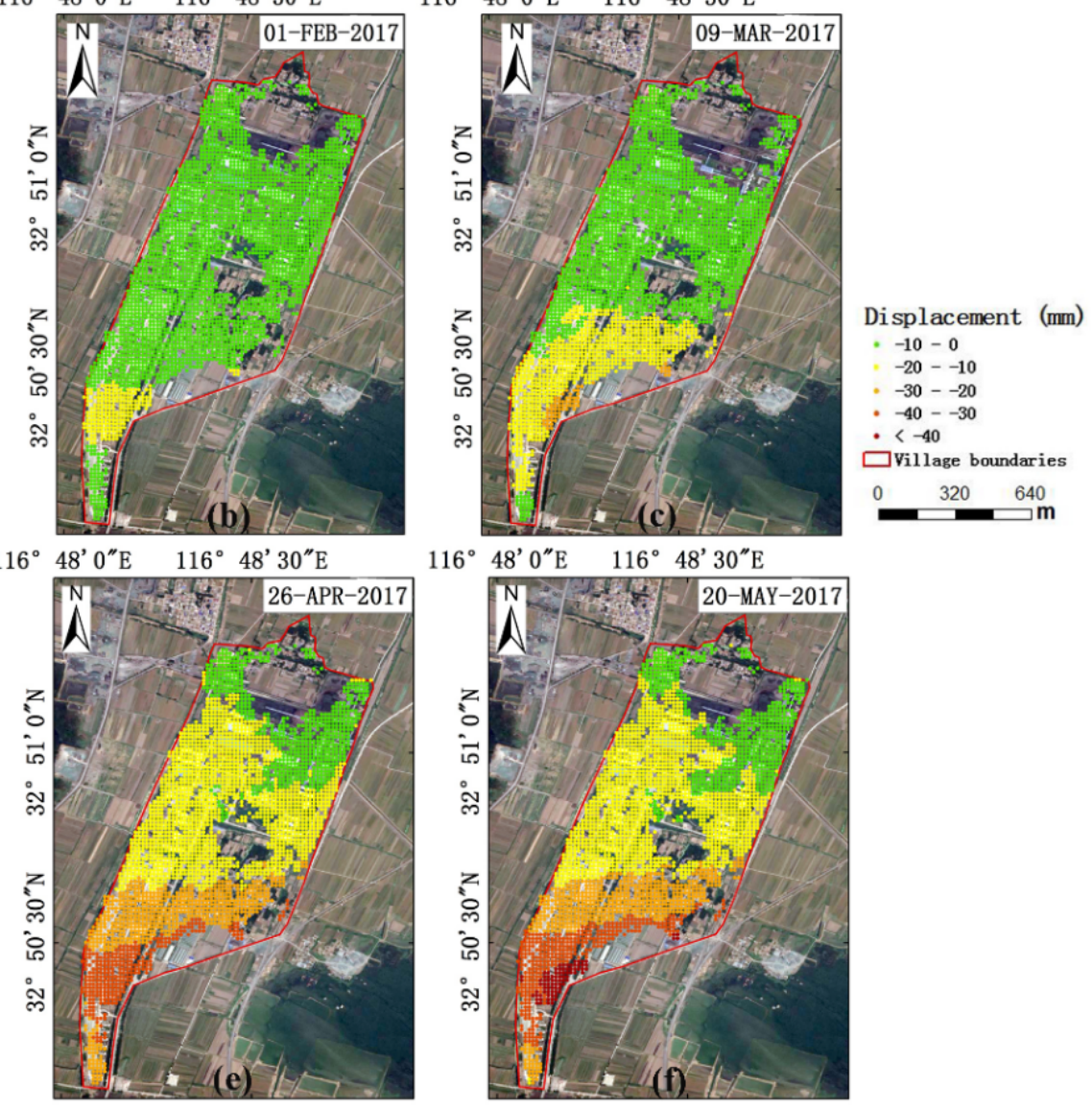

$116^{\circ} 48^{\prime} 0^{\prime \prime} \mathrm{E} \quad 116^{\circ} 48^{\prime} 30^{\prime \prime} \mathrm{E}$

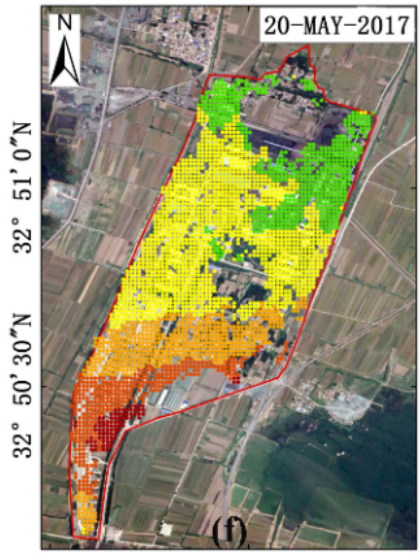

Figure 4: Deformation sequence of the study area (all maps refer to December 27, 2016): (a) January 8, 2017, (b) February 1, 2017, (c) March 9, 2017, (d) April 2, 2017, (e) April 26, 2017, and (f) May 20, 2017

model. The detailed data and results are shown in Tables 25 and Figure 6.

Figure 7 shows that the deformation sequences of the two observation points are similar during the observation period and demonstrate an overall growth trend. By comparison, in Figure 7 , the GM $(1,1)$ model, SVR model and
GM-SVR model proposed in this paper have better fitting effects at the two observation points. However, in the comparison of the forecasting results, the GM $(1,1)$ model shows unsatisfactory prediction results and large deviations, which is obviously lower than the accuracy of the SVR model and the model proposed in this paper. 


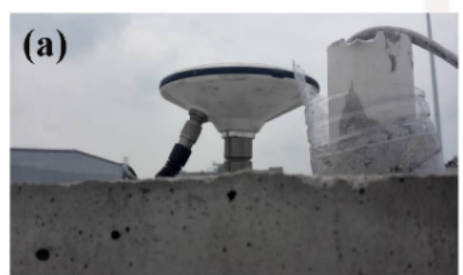

(b)

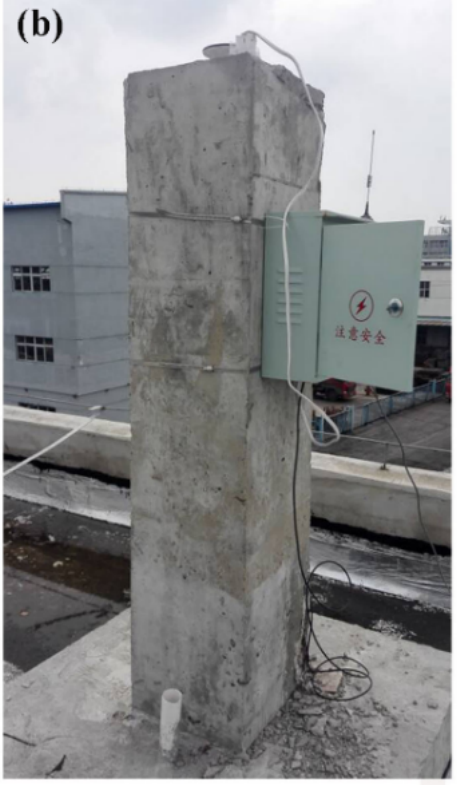

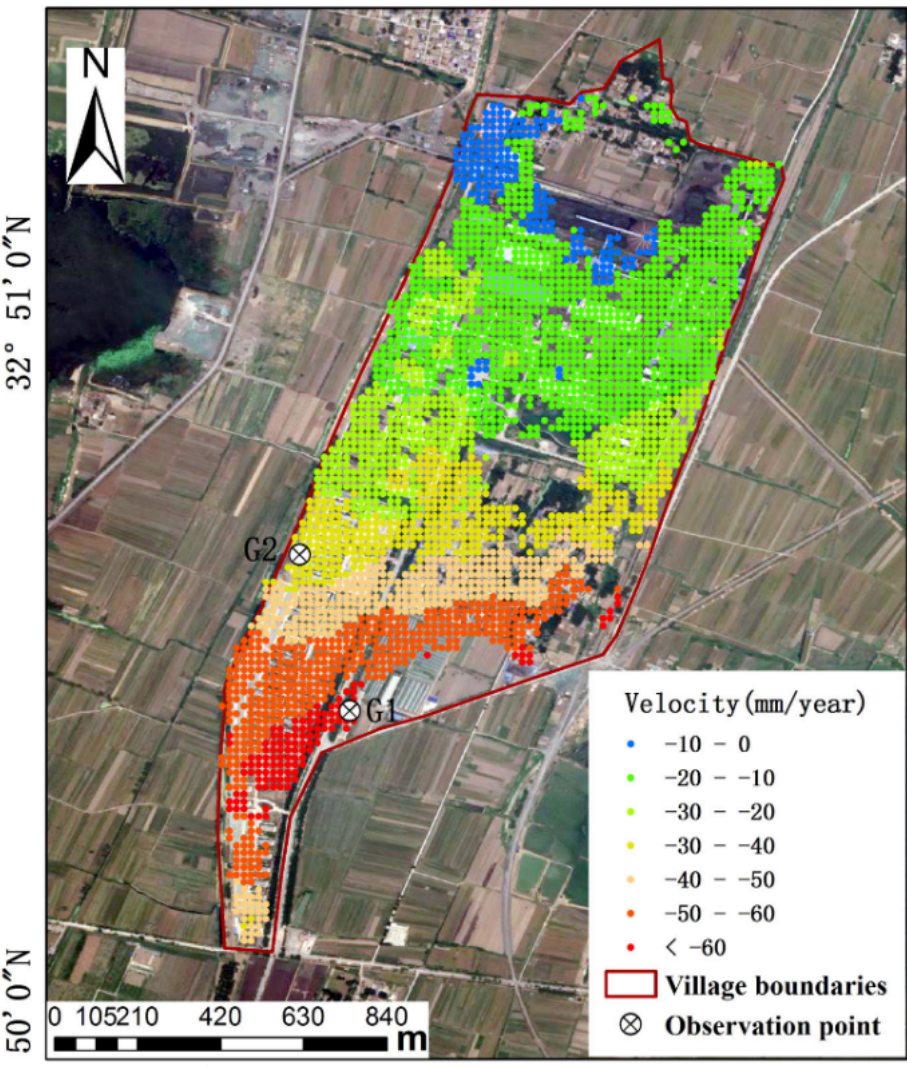

$116^{\circ} 48^{\prime} 0^{\prime \prime} \mathrm{E}$

(c)

Figure 5: Cumulative deformation rate of the study area and location of GPS station: (a), (b) GPS station, and (c) cumulative deformation rate

Table 3: Comparison of predicted results of each model in point $\mathrm{G} 1 / \mathrm{mm}$

\begin{tabular}{|c|c|c|c|c|c|c|c|c|}
\hline \multirow[t]{2}{*}{ No. } & \multirow{2}{*}{$\begin{array}{l}\text { Acquisition } \\
\text { date }\end{array}$} & \multirow{2}{*}{$\begin{array}{c}\text { SBAS } \\
\text { results } \\
/ \mathrm{mm}\end{array}$} & \multicolumn{2}{|c|}{ GM $(1,1)$ model } & \multicolumn{2}{|c|}{ SVR model } & \multicolumn{2}{|c|}{ GM-SVR model } \\
\hline & & & $\begin{array}{c}\text { forecast } \\
\text { result }\end{array}$ & $\begin{array}{l}\text { Relative } \\
\text { error } / \%\end{array}$ & $\begin{array}{c}\text { forecast } \\
\text { result }\end{array}$ & $\begin{array}{l}\text { Relative } \\
\text { error } / \%\end{array}$ & $\begin{array}{c}\text { forecast } \\
\text { result }\end{array}$ & $\begin{array}{l}\text { Relative } \\
\text { error/\% }\end{array}$ \\
\hline 1 & 2017.04 .14 & 33.89 & 40.76 & 20.27 & 35.47 & 4.66 & 32.27 & -4.78 \\
\hline 2 & 2017.04 .26 & 36.33 & 48.99 & 34.85 & 38.61 & 6.28 & 32.73 & -9.91 \\
\hline 3 & 2017.05 .08 & 38.09 & 58.88 & 54.58 & 42.16 & 10.69 & 35.24 & -7.48 \\
\hline 4 & 2017.05 .20 & 42.81 & 70.78 & 65.34 & 48.05 & 12.24 & 41.77 & -2.43 \\
\hline
\end{tabular}

Table 2 shows that during the observation period of the G1 point, the fitting effect of the three models are good and the result is relatively stable. Among the three models, the model proposed in this paper has the best fitting effect. The relative error is generally maintained below $2 \%$. Only the data of No.3 and No. 5 exceed $2 \%$. Table 3 shows the prediction results of the three models based on the training samples at the G1 point. It can be seen that the deviations between the predicted and the measured values of the grey model are relatively large; the SVR model and the GM-SVR model of this paper have relatively good results which are relatively stable and accurate. Table 4 shows the fitting results of the three models at G2. Differing from the result at G1, the fitting effect of the GM $(1,1)$ model and the SVR model is relatively poor, and the accuracy and stability of the fitting result are all reduced. The maximum relative errors of the fitting results of the GM $(1,1)$ model and the SVR model reach $52.8 \%$ and $-32.78 \%$, respectively. However, the results of the GM-SVR model still maintain high degrees of accuracy and stability. Table 5 shows the settlement prediction results of the three models at G2. Similar to the prediction result at G1, the accuracy of the GM $(1,1)$ 
Table 4: Comparison of fitting results in each model of $\mathrm{G} 2 / \mathrm{mm}$

\begin{tabular}{ccccccccc}
\hline No. & $\begin{array}{c}\text { Acquisition } \\
\text { date }\end{array}$ & $\begin{array}{c}\text { SBAS } \\
\text { results } \\
\end{array}$ & & \multicolumn{2}{c}{ GM (1, 1) model } & \multicolumn{2}{c}{ SVR model } & \multicolumn{2}{c}{ GM-SVR model } \\
\cline { 3 - 9 } & & Fitting & $\begin{array}{c}\text { Relative } \\
\text { value }\end{array}$ & $\begin{array}{c}\text { Fitting } \\
\text { error/\% }\end{array}$ & $\begin{array}{c}\text { Relative } \\
\text { value }\end{array}$ & $\begin{array}{c}\text { Fitting } \\
\text { error } / \%\end{array}$ & $\begin{array}{c}\text { Relative } \\
\text { value }\end{array}$ & error $\%$ \\
\hline 1 & 2017.01 .08 & 1.51 & 1.51 & 0 & 1.57 & 3.97 & 1.52 & 0.66 \\
2 & 2017.01 .20 & 2.41 & 3.02 & 25.3 & 1.62 & -32.78 & 2.38 & -1.24 \\
3 & 2017.02 .01 & 2.61 & 3.99 & 52.8 & 2.67 & 2.3 & 2.62 & 0.38 \\
4 & 2017.02 .13 & 4.03 & 5.27 & 30.77 & 4.67 & 15.88 & 4.04 & 0.25 \\
5 & 2017.02 .25 & 7.26 & 6.95 & -4.27 & 7.31 & 0.69 & 6.85 & -5.65 \\
6 & 2017.03 .09 & 10.17 & 9.17 & -9.83 & 10.08 & -0.88 & 10.18 & 0.1 \\
7 & 2017.03 .21 & 12.75 & 12.11 & -5.02 & 12.41 & -2.67 & 12.73 & -0.16 \\
8 & 2017.04 .02 & 13.83 & 15.98 & 15.55 & 13.89 & 0.43 & 13.84 & 0.07 \\
\hline
\end{tabular}

Table 5: Comparison of predicted results of each model in point $\mathrm{G} 2 / \mathrm{mm}$

\begin{tabular}{ccccccccc}
\hline No. & $\begin{array}{c}\text { Acquisition } \\
\text { date }\end{array}$ & $\begin{array}{c}\text { SBAS } \\
\text { results }\end{array}$ & \multicolumn{2}{c}{ GM $(\mathbf{1 , 1}$ model } & \multicolumn{2}{c}{ SVR model } & \multicolumn{2}{c}{ GM-SVR model } \\
\cline { 5 - 9 } & & forecast & Relative & forecast & Relative & forecast & $\begin{array}{c}\text { Relative } \\
\text { error } / \%\end{array}$ \\
\hline 1 & 2017.04 .14 & 15.42 & 21.08 & 36.71 & 14.35 & -6.94 & 14.17 & -8.11 \\
2 & 2017.04 .26 & 17.18 & 27.82 & 61.93 & 13.89 & -19.15 & 15.58 & -9.31 \\
3 & 2017.05 .08 & 19.86 & 36.72 & 84.89 & 12.81 & -35.5 & 20.24 & 1.91 \\
4 & 2017.05 .20 & 25.21 & 48.45 & 92.19 & 17.47 & -30.7 & 29.91 & 18.64 \\
\hline
\end{tabular}

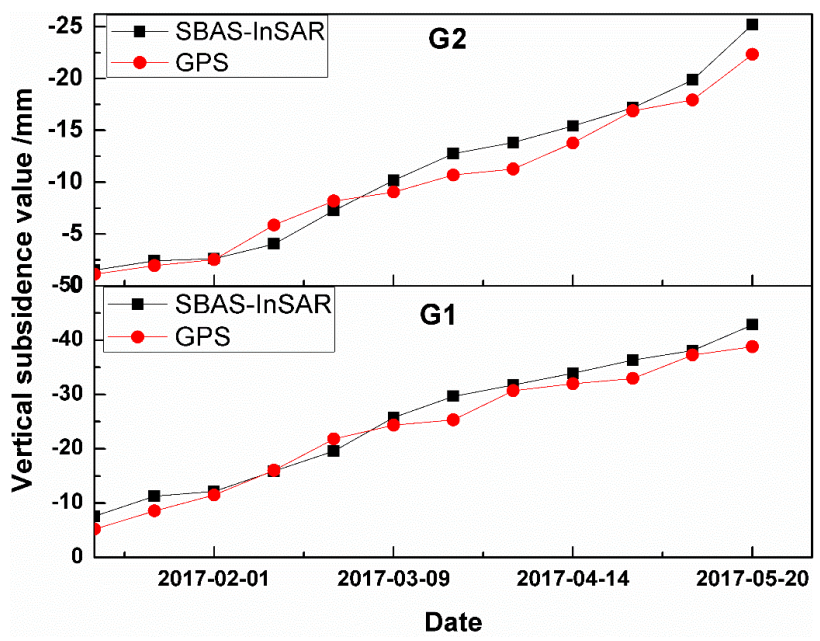

Figure 6: Comparison of the vertical deformation time series of two observation points obtained by SBAS-InSAR and GPS

model at $\mathrm{G} 2$ is still not high. In contrast to the prediction result at G1 point, the prediction effect of the SVR model at G2 is not ideal, and the maximum relative error even reaches $-35.5 \%$. Only the prediction results of the GM-SVR model are similar to those predicted at G1, and still maintain high accuracy and stability. The relative error of the GM-SVR results is generally maintained below $10 \%$. Based on this, for the deformation sequence in this study area, the GM $(1,1)$

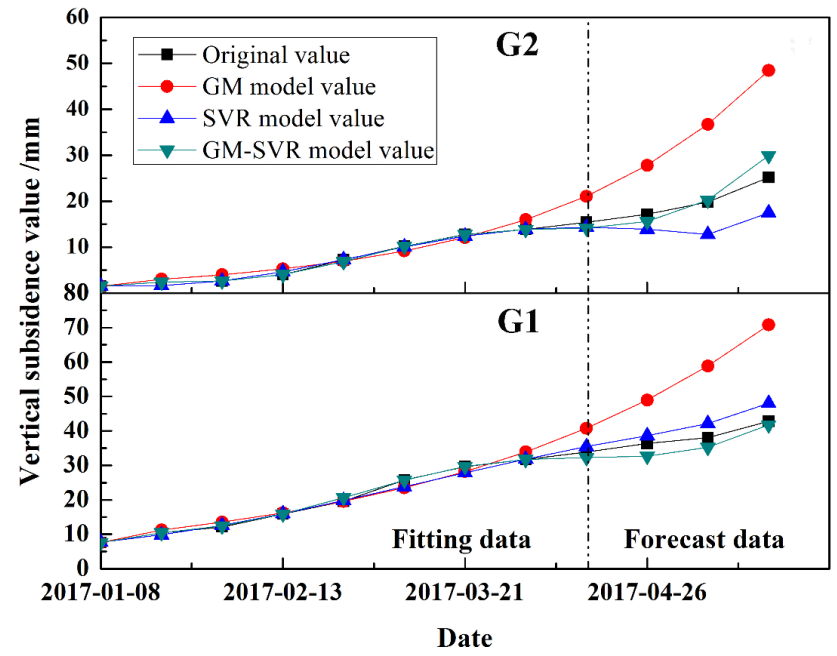

Figure 7: Comparison of the original values of the observation points and the results of the three models

model prediction result is not ideal and has essentially deviated from the monitoring value; the prediction result of a single SVR model is not sufficiently stable, and only the GM-SVR model result shows high accuracy and stability.

To test a model's accuracy, there are generally three methods: residual size, correlation degree, and posterior error. To evaluate the performance of the model more comprehensively and intuitively, this paper proposes to eval- 
Table 6: Accuracy comparison of each model / $\mathrm{mm}$

\begin{tabular}{ccccc}
\hline & & GM $(1,1)$ model & SVR model & GM-SVR model \\
\hline Root Mean Square Error & G1 point & 10.94 & 2.22 & 1.47 \\
& G2 point & 9.03 & 3.19 & 1.48 \\
Mean Absolute Error & G1 point & 6.39 & 1.54 & 0.88 \\
& G2 point & 5.31 & 1.77 & 0.7 \\
\hline
\end{tabular}

uate the accuracy of the model using two indicators, root mean square error (RMSE) and mean absolute error (MAE). The results are shown in Table 6.

\section{Discussion}

With the large-scale development and utilization of mineral resources, a series of environmental problems that are caused by mining have gradually emerged, the most direct impacted is the ground subsidence of a mining area. Ground subsidence will destroy the land, buildings, transportation facilities, pipeline facilities, etc. of a mining area and greatly interfere with the daily lives of the people who occupy the mining area. Therefore, long-term dynamic monitoring and prediction of surface deformations in the mining area is urgently needed to understand the subsidence laws and damage degrees of the mining area; to predict the location, nature and scale of the possible disasters; and to minimise the adverse impacts of disasters on mining areas.

In this paper, using SBAS-InSAR technology, the Yang Juzhaung research area was continuously monitored by 13 Sentinel-1A images. The monitoring results are shown in Figures 4 and 5. The comparison of the deformation sequence observations of the observation points by GPS and SBAS-InSAR technology verifies that the SBAS-InSAR technology monitors the settlements in the residential area with millimetre-level accuracy and meets the requirements for deformation monitoring for mine measurements [52]. The results show that during the period from December 2016 to May 2017, severe subsidence occurred in the study area. The displacement of the entire residential area gradually increased from north to south, and the deformation rate accelerated significantly, thus forming a clear subsidence funnel. It can be speculated that if the study area continues to maintain such a settlement trend, then the affected area will continue to increase. This may cause damage to buildings in residential areas and affect the safety of residents' lives and property. In addition, after finding the local geological and hydrological data, the diving level in the study area was found to be high, and water accumulation occurred when the surface sunk by approximately 2 metres. Therefore, special attention should be paid to this area to avoid further disasters caused by the continued increase in land subsidence that could result in further economic losses and casualties.

The GM-SVR model proposed in this paper is compared with the accuracy of the other two traditional models. The comparison results are shown in Table 6. As can be seen from Table 6, the prediction accuracy of the GM $(1,1)$ model is low, and the root mean square errors of both points are close to $10 \mathrm{~mm}$. Compared with the GM $(1,1)$ model, the SVR model shows better accuracy, but the stability of the model's prediction results is not sufficient. Only the GM-SVR model maintains good global forecasting capabilities, and each index of this model is better than the other two models. This model integrates the advantages of the GM $(1,1)$ model for linear data and the support vector machine models for nonlinear data processing and uses the advantages of strong generalization abilities and excellent learning abilities of the support vector machine model to convert the nonlinear residual generated by the grey model to a high-dimensional linear problem. A high-precision and widely applicable combination forecasting model with time series as input was successfully constructed. Although the settlement value can be predicted more accurately by using the GM-SVR model, this paper only makes numerical predictions for settlement, and does not make good use of the prediction results for disaster assessments in the field. For example, this study does not address how to use the prediction results to assess the damage level of buildings in the study area or how to determine the range of possible disasters based on the prediction results. Resolving these questions constitute the current objectives of the research group.

\section{Conclusion}

In this paper, SBAS-InSAR technology is used to monitor and analyse deformations of residential areas caused 
by coal mining, and the consecutive time deformation sequences in the study area from December 27, 2016 to May 20, 2017 were obtained. Based on the actual deformation characteristics of mining subsidence in mining areas, a reliable deformation prediction model was established. Finally, by using the monitoring results of SBAS-InSAR, a high-precision deformation prediction of the mining area was performed through the GM-SVR model, which provided powerful data for the prevention of disasters.

The monitoring results show that Yang Juzhuang, which is in the study area, has been affected by underground coal mining activities since monitoring began in December 2016. The maximum deformation rate reached -90 mm/year. Until May 20, 2017, the maximum cumulative vertical settlement was $48 \mathrm{~mm}$.

The GM-SVR model presented in this paper can satisfactorily predict the deformation of this study area. Compared with the traditional prediction model for the complex deformation caused by mining, the excellent performance of the GM-SVR model is highlighted. The root mean square error of the model's prediction results is less than $2 \mathrm{~mm}$, and the mean absolute error is less than $1 \mathrm{~mm}$. This model is of great significance in enabling the provision of early warnings for mining disasters and the safe maintenance of the life and property of the residents in mining areas.

The combination of the GM-SVR model and SBASInSAR can achieve rapid dynamic monitoring and disaster warnings in the region. This study is also an important reference for preventing similar disasters.

Acknowledgement: The paper was funded by special project of National Key Laboratory of Mapping, Remote Sensing and Information Engineering in China (16P02), the views expressed are the authors' alone. We are thankful to the editor and anonymous reviewers for their constructive comments, which greatly help to improve the original manuscript.

\section{References}

[1] Steiakakis C., Agioutantis Z., Apostolou E., Papavgeri G., \& Tripolitsiotis A., Integrating weather and geotechnical monitoring data for assessing the stability of large scale surface mining operations. Open Geosciences, 2016, 8(1): 694-699.

[2] Svartsjaern M., A Prognosis Methodology for Underground Infrastructure Damage in Sublevel Cave Mining. Rock Mechanics \& Rock Engineering, 2018(6):1-17.

[3] Guo H., Kang Z., Coal mining induced land subsidence monitoring using multiband spaceborne differential interferometric synthetic aperture radar data. Journal of Applied Remote Sensing
2011, 5(14):3518.

[4] Can E., Mekik C., Kuscu S., Subsidence occurring in mining regions and a case study of Zonguldak-Kozlu basin. Scientific Research \& Essays, 2011, 6(6):1317-1327.

[5] Can E., Şenol Kuşcu, Mekik C., Determination of underground mining induced displacements using GPS observations in zonguldak-kozlu hard coal basin. International Journal of Coal Geology, 2012, 89(1): 62-69.

[6] Li W. X., Wen L., Liu X. M., Ground movements caused by deep underground mining in Guan-Zhuang iron mine, Luzhong, China. International Journal of Applied Earth Observation \& Geoinformation, 2010, 12(3):175-182.

[7] Chen S., Yin D., Cao F., An overview of integrated surface subsidence-reducing technology in mining areas of China. Natural Hazards, 2016, 81(2):1129-1145.

[8] Can E., Şenol Kuşcu, Mekik C., Determination of underground mining induced displacements using GPS observations in Zonguldak-Kozlu Hard Coal Basin. International Journal of Coal Geology, 2012, 89(1):62-69.

[9] Gayarre F. L., Álvarez-Fernández M. I., González-Nicieza C., et al. Forensic analysis of buildings affected by mining subsidence. Engineering Failure Analysis, 2010, 17(1):270-285

[10] Sarupria M., Manjare S. D., Girap M., Environmental impact assessment studies for mining area in Goa, India, using the new approach. Environmental Monitoring and Assessment, 2019, 191(1).

[11] Wang Z., Yu S., Tao Q., et al. A method of monitoring threedimensional ground displacement in mining areas by integrating multiple InSAR methods. International Journal of Remote Sensing, 2018, 39(4):1199-1219.

[12] Longoni L., Papini M., Brambilla D., Arosio D., \& Zanzi L., The risk of collapse in abandoned mine sites: the issue of data uncertainty. Open Geosciences, 2016, 8(1): 246-258.

[13] Jia L. G., Sun K. H., Neural Network Prediction of Ground Surface Settlement under the Influence of Open Pit Mining. Advanced Materials Research, 2014, 1073-1076:2128-2134.

[14] Muntean A., Mocanu V., Ambrosius B., A GPS study of land subsidence in the Petrosani (Romania) coal mining area. Natural Hazards, 2016, 80(2):1-14.

[15] Zhang A. B., Zhang Z. J., Gao J. X., Feasibility study on mining surface subsidence high-precision monitoring using GPS. Journal of China Coal Society, 2009.

[16] Szczerbowski Z., Mining Induced Seismic Events and Surface Deformations Monitored by GPS Permanent Stations. Acta Geodynamica Et Geomaterialia, 2015, 12(3):237-248.

[17] Bogusz J., Gruszczynski M., Figurski M., \& Klos A., Spatiotemporal filtering for determination of common mode error in regional GNSS networks. Open Geosciences, 2015, 7(1).

[18] Bhattacharya A., Mukherjee K., Review on InSAR based displacement monitoring of Indian Himalayas: issues, challenges and possible advanced alternatives. Geocarto International, 2016, 32(3):298-321.

[19] Peduto D., Nicodemo G., Maccabiani J., Multi-scale analysis of settlement-induced building damage using damage surveys and DInSAR data: A case study in The Netherlands. Engineering Geology, 2017, 218:117-133.

[20] Zebker H. A., Goldstein R. M., Topographic mapping from interferometric synthetic aperture radar observations. Journal of Geophysical Research Solid Earth, 1986, 91(B5):4993-4999.

[21] Zhu B., Li J., Chu Z., et al. A Robust and Multi-Weighted Approach to Estimating Topographically Correlated Tropospheric Delays in 
Radar Interferograms. Sensors, 2016, 16(7):1078.

[22] Berardino P., Fornaro G., Lanari R., A new algorithm for surface deformation monitoring based on small baseline differential SAR interferograms. IEEE Transactions on Geoscience \& Remote Sensing, 2003, 40(11):2375-2383.

[23] Huang J., Khan S. D., Ghulam A., Study of Subsidence and Earthquake Swarms in the Western Pakistan. Remote Sensing, 2016, 8(11):1-17.

[24] Lanari R., Berardino P., Bonano M., Surface displacements associated with the L'Aquila 2009 Mw 6.3 earthquake (central Italy): New evidence from SBAS-DInSAR time series analysis. Geophysical Research Letters, 2010, 37(20).

[25] Samsonov S., Beavan J., González P. J., Ground deformation in the Taupo Volcanic Zone, New Zealand, observed by ALOS PALSAR interferometry. Geophysical Journal International, 2011, 187(1):147-160.

[26] Necsoiu M., Onaca A., Wigginton S., Rock glacier dynamics in Southern Carpathian Mountains from high-resolution optical and multi-temporal SAR satellite imagery. Remote Sensing of Environment, 2016, 177:21-36.

[27] Euillades L. D., Euillades P. A., Riveros N. C., Detection of glaciers displacement time-series using SAR. Remote Sensing of Environment, 2016, 184:188-198.

[28] Castellazzi P., Martel R., Rivera A., Groundwater depletion in Central Mexico: Use of GRACE and InSAR to support water resources management. Water Resources Research, 2016, 52(8):59856003.

[29] Reeves J. A., Knight R., Zebker H. A., An Analysis of the Uncertainty in InSAR Deformation Measurements for Groundwater Applications in Agricultural Areas. IEEE Journal of Selected Topics in Applied Earth Observations \& Remote Sensing, 2014, 7(7):2992 3001.

[30] Zhang Z., Wang C., Tang Y., Analysis of ground subsidence at a coal-mining area in Huainan using time-series InSAR. International Journal of Remote Sensing, 2015, 36(23):5790-5810.

[31] Gee D., Bateson L., Sowter A., Ground Motion in Areas of Abandoned Mining: Application of the Intermittent SBAS (ISBAS) to the Northumberland and Durham Coalfield, UK. Geosciences, 2017, 7(3):85.

[32] Liu X., Wang Y., Yan S., Ground deformation associated with exploitation of deep groundwater in Cangzhou City measured by multi-sensor synthetic aperture radar images. Environmental Earth Sciences, 2017, 76(1):6.

[33] Novellino A., Cigna F., Sowter A., Exploitation of the Intermittent SBAS (ISBAS) algorithm with COSMO-SkyMed data for landslide inventory mapping in north-western Sicily, Italy. Geomorphology, 2017, 280:153-166.

[34] Luca C. D., Zinno I., Manunta M., Large areas surface deformation analysis through a cloud computing P-SBAS approach for massive processing of DInSAR time series. Remote Sensing of Environment, 2017.

[35] Scifoni S., Bonano M., Marsella M., On the joint exploitation of long-term DInSAR time series and geological information for the investigation of ground settlements in the town of Roma (Italy). Remote Sensing of Environment, 2016, 182:113-127.

[36] Shafaei M., Kisi O., Lake Level Forecasting Using Wavelet-SVR, Wavelet-ANFIS and Wavelet-ARMA Conjunction Models. Water Resources Management, 2016, 30(1):79-97.
[37] Fattahi H., Application of improved support vector regression model for prediction of deformation modulus of a rock mass. Engineering with Computers, 2016, 32(4):567-580.

[38] Hong H., Pradhan B., Jebur M. N., Spatial prediction of landslide hazard at the Luxi area (China) using support vector machines. Environmental Earth Sciences, 2016, 75(1):1-14.

[39] Hu Z., Xiao W., Optimization of concurrent mining and reclamation plans for single coal seam: a case study in northern Anhui, China. Environmental Earth Sciences, 2013, 68(5):1247-1254.

[40] Dong S., Samsonov S., Yin H., Spatio-temporal analysis of ground subsidence due to underground coal mining in Huainan coalfield, China. Environmental Earth Sciences, 2015, 73(9):55235534.

[41] Hadjimitsis D. G., Advances in remote sensing and geoinformation for the environment. Open Geosciences, 2014, 6(1):11.

[42] Whelen T., Siqueira P., Time-series classification of Sentinel-1 agricultural data over North Dakota. Remote Sensing Letters, 2018, 9(5):411-420.

[43] Ardhuin F., Stopa J., Chapron B., Measuring ocean waves in sea ice using SAR imagery: A quasi-deterministic approach evaluated with Sentinel-1 and in situ data. Remote Sensing of Environment, 2017, 189:211-222.

[44] Saro L., Woo J. S., Kwanyoung 0., The spatial prediction of landslide susceptibility applying artificial neural network and logistic regression models: A case study of Inje, Korea. Open Geosciences, 2016, 8(1):117-132.

[45] Lanari R., Mora O., Manunta M., A small-baseline approach for investigating deformations on full-resolution differential SAR interferograms. Geoscience \& Remote Sensing IEEE Transactions on, 2004, 42(7):1377-1386.

[46] Manunta M., Marsella M., Zeni G., Two-scale surface deformation analysis using the SBAS-DInSAR technique: a case study of the city of Rome, Italy. International Journal of Remote Sensing, 2008, 29(6):1665-1684.

[47] Mao M., Chirwa E. C., Application of grey model GM $(1,1)$ to vehicle fatality risk estimation. Technological Forecasting \& Social Change, 2006, 73(5):588-605.

[48] Xiao X., Deng J., A New Modified GM $(1,1)$ Model: Grey Optimization Model. Journal of Systems Engineering and Electronics, 2001, 12(2):1-5.

[49] Tong H., Chen D. R., Peng L., Analysis of Support Vector Machines Regression. Foundations of Computational Mathematics, 2009, 9(2):243-257.

[50] Christmann A., Steinwart I., Consistency and Robustness of Kernel-Based Regression in Convex Risk Minimization. Bernoulli, 2007, 13(3):799-819.

[51] Mokarram M., Sathyamoorthy D., Relationship between landform classification and vegetation (case study: southwest of Fars province, Iran). Open Geosciences, 2016, 8(1):302-309.

[52] Diao X., Wu K., Zhou D., Integrating the probability integral method for subsidence prediction and differential synthetic aperture radar interferometry for monitoring mining subsidence in Fengfeng, China. Journal of Applied Remote Sensing, 2016, 10(1):016028. 